\title{
Iconicity, Implicature, and the Manner Interpretation of Coordination Structure: Through Comparison of English and French
}

DAVID Y. OSHIMA

Nagoya University

\section{Introduction}

This paper discusses conditions under which a VP-coordination structure ('Subj. $\mathrm{VP}_{1}$ and $\mathrm{VP}_{2}$ ') may conversationally implicate a manner relation between the two described events, based on data from English and French. It will be pointed out that two factors affect the availability of the manner interpretation. First, the principle of iconicity dictates that, other things being equal, subordination structure is more suitable than coordination structure in describing two actions standing in the manner relation. Second, whether the VP-coordination structure in a given language allows the manner interpretation at all or not is determined by its 'niche', i.e., its standing in the network of constructions.

Section 1 illustrates basic data and two 'puzzles' concerning the manner interpretation of coordination structure. It will be shown that in English, the VPcoordination structure with and allows a manner interpretation but under limited conditions (the problem of intra-linguistic requirement), and that in French, the corresponding structure with et does not allow a manner interpretation at all (the problem of cross-linguistic variation). Section 2 points out that the manner interpretation of the English VP-coordination structure is blocked when the two described events stand in a whole-part relation, and argues that this is an effect of the principle of iconicity. Section 3 discusses why the French VP-coordination structure, unlike its English counterpart, does not allow the manner interpretation at all. It will be argued that the difference between them can be attributed to the fact that the former has a strong rival construction (namely the gérondif) which preempts the use of the coordination construction. 


\section{David Y. Oshima}

\section{$1 \quad$ Two Puzzles}

It is widely known that conjunctive coordination structure ${ }^{1}$ (e.g., $S_{1}$ and $S_{2}$ ) tends to undergo semantic enrichment, due to Gricean conversational implicature. Levinson (2000) illustrates this phenomenon, known as conjunction buttressing, with examples like the following (the symbol $+>$ is read as 'conversationally implicates'; +/> means 'does not conversationally implicate').

(1) John turned the key and the engine started.

$+>$ ' $p$ and then q' (subsequence)

$+>$ 'p therefore q' (causal connectedness)

$+>$ 'A did X to cause q' (teleology, intentionality)

(adapted from Levinson 2000:117)

The English VP-coordination construction (Subj. $V P_{1}$ and $\left.V P_{2}\right)$ allows what can be loosely called the manner interpretation, where the action/event described by the first conjunct is understood as the manner in which the action/event described by the second conjunct took place. Examples are given below (assume that the function of the button referred to in $(2 \mathrm{a})$ is to operate the door, rather than just to unlock it):

(2) a. David pressed the button and opened the (automatic) door.

$+>$ Pressing the button is the manner of opening the door.

b. David poured hot water on the ice and melted it.

$+>$ Pouring hot water is the manner of melting the ice.

Such sentences can be paraphrased with a free adjunct construction (among other possibilities), as shown in (3):

(3) a. David opened the door pressing the button.

b. David melted the ice pouring hot water on it.

The VP-coordination constructions given in (4), however, do not implicate, and actually implicates the absence of, the manner relation (\# indicates the unavailability of the intended interpretation). ${ }^{2}$

\footnotetext{
1 Throughout the paper, I will use the term coordination structure (construction) to refer to the conjunctive coordination structure (construction), and thus exclude disjunctive coordination structure with or, etc.

${ }^{2}$ With appropriate contextualization and some modification, a sentence like (4a) would allow the manner interpretation (thanks to Eve Sweetser to point this out):

(i) Paul has hidden David's fork to stop him from eating the fried noodles. David, however, used chopsticks and ate the noodles.

(4a) still contrasts with $(2 a, b)$, which allow the manner interpretation without much contextualization.
} 
a. \#David used chopsticks and ate fried noodles.

$+>$ Using chopsticks is the manner of eating fried noodles.

$+>$ Using chopsticks is not the manner of eating fried noodles.

b. \#David shook his head and danced.

+> Shaking one's head is the manner of dancing.

$+>$ Shaking one's head is not the manner of dancing.

The manner interpretation can be expressed (perhaps implicated) by the corresponding free adjunct constructions shown in (5); thus, (5) cannot be taken as paraphrases of (4) in the way (3) can of (2).

a. David ate fried noodles using chopsticks.

b. David danced shaking his head.

This contrast constitutes our first puzzle, the problem of language-internal requirement: under what conditions does a coordinating construction allow the manner interpretation? One may hypothesize that only the relation of means-end (or instrumentality), which is a special subtype of the manner relation, can be expressed by coordination structure. While this generalization correctly predicts the unavailability of the manner interpretation for (4b), it does not account for the case of (4a), where David's using chopsticks is obviously the means of his eating fried noodles. In fact, the intended interpretation of (4a) can be expressed with explicit markers of the means-end relation, such as by and in order to, although such sentences may sound somewhat awkward.

a. David opened the door by pressing the button.

b. David melted the ice by pouring hot water on it.

c. (?)David ate fried noodles by using chopsticks.

d. \#David danced by shaking his head.

a. David pressed the button in order to open the door.

b. David poured hot water on the ice in order to melt it.

c. (?)David used chopsticks in order to eat fried noodles.

d. \#David shook his head in order to dance.

Besides, while it may be the case that non-instrumental manner relations cannot be expressed by coordination structure, it is yet to be explained why this must be the case.

Turning now to a second puzzle, VP-coordination structures in some other languages do not (easily) allow the manner interpretation. Kortmann (1991:164, citing Pusch (1980)), notes that languages such as French and Italian "lack instrumental conjunctions." Thus, the French coordinating constructions in (8) do not implicate the manner relation between the two events, despite the fact that 


\section{David Y. Oshima}

they are fairly faithful translations of $(2) .^{3}$
a. \#David a appuyé sur le bouton et a
David Aux press(PstPrt) on the button and Aux
ouvert la porte.
open(PstPrt) the door
'David pressed the button and opened the door.'
b. \#David a versé de l' eau chaude sur la glace
David Aux pour(PstPrt) P.Art water hot on the ice
et l'a fait fondre.
and it Aux make(PstPrt) melt
'David poured hot water on the ice and melted it.'

The intended manner interpretation can be naturally expressed with the gérondif construction, which is reminiscent of the English present-participial free adjunct in terms of both form and function.

a. David a ouvert la porte en appuyant sur

David Aux open(PstPrt) the door in press(PrsPrt) on

le bouton.

the button

'David opened the door by pressing the button.'
b. David a fait fondre la glace en $y$
David Aux make(PstPrt) melt the ice in there
versant de l' eau chaude.
pour(PrsPrt) P.Art water hot
'David melted the ice by pouring hot water on it.'

The French sentences corresponding to (4), presented in (10), likewise do not allow the manner interpretation; the versions with the gérondif, given in (11), do. ${ }^{4}$
a. \#David a utilisé des baguettes et a
David Aux use(PstPrt) I.Art chopsticks and Aux
mangé des nouilles sautées.
eat(PstPrt) I.Art noodles sautéed
'David used chopsticks and ate fried noodles.'
b. \#David a secoué la tête et a dansé.
David Aux shake(PstPrt) the head and Aux dance(PstPrt)
'David shook his head and danced.'

\footnotetext{
3 The abbreviations in the glosses are: Acc $=$ accusative, Aux $=$ auxiliary verb, Dcl $=$ declarative, Ger $=$ gerund, $\mathrm{I}$. Art $=$ indefinite article, $\mathrm{Inf}=$ infinitive, $\mathrm{P}$. Art $=$ partitive article, PrsPrt $=$ present participle, Pst $=$ past, PstPrt $=$ past participle.

${ }^{4}$ (11a) sounds prolix and less natural than the version with the preposition avec 'with', i.e., David a mangé des nouilles sautées avec des baguettes 'David ate fried noodles with chopsticks'.
} 
a. (?)David a mangé des nouilles sautées en David Aux eat(PstPrt) I.Art noodles sautéed in utilisant des baguettes. use(PrsPrt) I.Art chopsticks 'David ate fried noodles using chopsticks.'

b. David a dansé en secouant la tête. David Aux dance(PstPrt) in shake(PrsPrt) the head 'David danced shaking his head.'

The manner interpretation becomes available for sentences like (8) if an adverbial like ainsi 'in this way' is inserted after the connective et 'and', as in (12).

(12) a. David a appuyé sur le bouton et ainsi a ouvert la porte. 'David pressed the button and thus opened the door.'

b. David a versé de l'eau chaude sur la glace et ainsi l'a fait fondre.

'David poured hot water over the ice and thus melted it.'

It becomes available also when it is contextually understood that the subject did not have an intention to cause the second event; thus, (8a) can felicitously describe a situation where a toddler named David pressed the button out of curiosity, without knowing that it was an operating switch of the door.

Where does this cross-linguistic difference stem from? In other words, what divides languages into two groups, ones where coordination constructions allow a manner interpretation (besides English, German and Russian apparently belong to this group), and ones where they do not (French, Italian, etc.). ${ }^{5}$ This is our second puzzle, the problem of cross-linguistic variation. The following sections will seek solutions to the two presented puzzles.

\section{Language-Internal Requirement}

The contrast between (2) and (4), repeated below as (13) and (14), can be attributed to iconic motivation, i.e., tendency and preference for the relation between linguistic forms to somehow reflect the relation between these forms' contents (Haiman 1980). ${ }^{6}$

(13) a. David pressed the button and opened the door.

b. David poured hot water on the ice and melted it.

\footnotetext{
${ }^{5}$ It is possible that this contrast is related in some way to the verb-framed vs. satellite-framed distinction. (Thanks to Oana David for bringing this point to my attention.)

${ }^{6}$ A paradigmatic example of iconic motivation is that of temporal sequence: other things being equal, the order in which clauses or statements are arranged corresponds to the order of the events they describe (see (1)). Another well-known example is reduplication, which conveys such information as intensity, plurality, and repetition.
} 


\section{David Y. Oshima}

(14) a. \#David used chopsticks and ate fried noodles.

b. \#David shook his head and danced.

In coordinating structure, two clauses, VPs or constituents of some other grammatical category of equal status, are conjoined together by a connective. The relation between the two conjuncts can be characterized as 'symmetric' and 'distinct,' and can be schematized as in Figure 1. In subordinating structure in contrast, one clause is embedded under and dependent on another clause. Here, the relation between the two clauses can be characterized as 'asymmetric' and

'fused,' and schematized as in Figure 2.Figure 1: Coordination structure

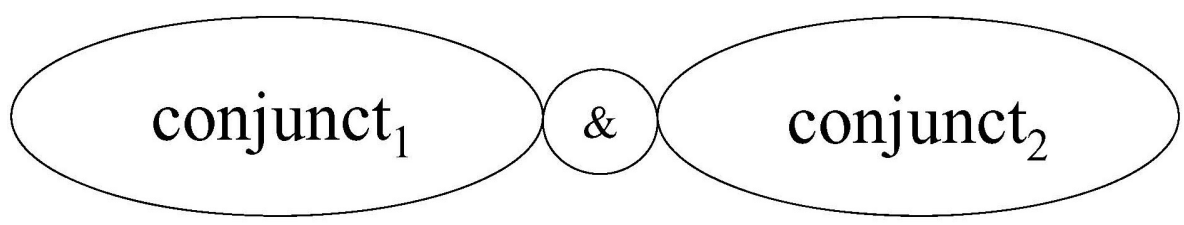

Figure 2: Subordination structure

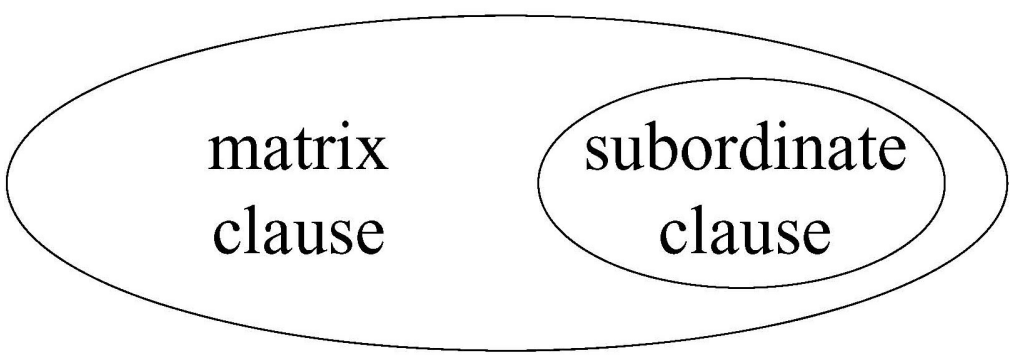

Let us now turn to the side of content. There has been much debate in the philosophical and linguistic literature as to how events and actions are ontologically and cognitively individuated, and under what conditions two actions/events are considered to stand in anidentity or part-whole relation (Pfeifer 1989; Zucchi 1993; Casati and Varzi 2010). The philosopher Anscombe asks the following question:

Are we to say that the man who (intentionally) moves his arm, operates the pump, replenishes the water supply, poisons the inhabitants, is performing four actions? Or only one? (Anscombe 1976:45)

One may likewise ask whether the two conjuncts in $(13 a, b)$ are descriptions of two distinct actions, or rather are of a single action. Is David's pressing the button 
to be regarded as the same action as his opening the door? Is his pouring hot water the same action as his melting the ice? My aim here is not to argue for either view, but is to highlight the fact that in such sentences the two described actions have largely overlapping extents so that they may reasonably be argued to be identical or near-identical. In the situations of $(14 a, b)$, in contrast, the first-clause action constitutes only a proper subpart of the action described in the second clause. Not using chopsticks alone, but a combination of it and other actions such as opening one's mouth, chewing, and swallowing constitute eating. Also, shaking one's head alone does not count as dancing, but it needs to be coordinated with motions of other body parts. The situations described in sentences like (13a, b) can be labeled as 'manner as the whole action' and schematized as in Figure 3. The situations which sentences like (14a, b) fail to describe - and for which subordination constructions like $(5 \mathrm{a}, \mathrm{b})$ are suitable - can be labeled as 'manner as part of the action' and schematized as in Figure 4.

Figure 3: Manner as the whole action
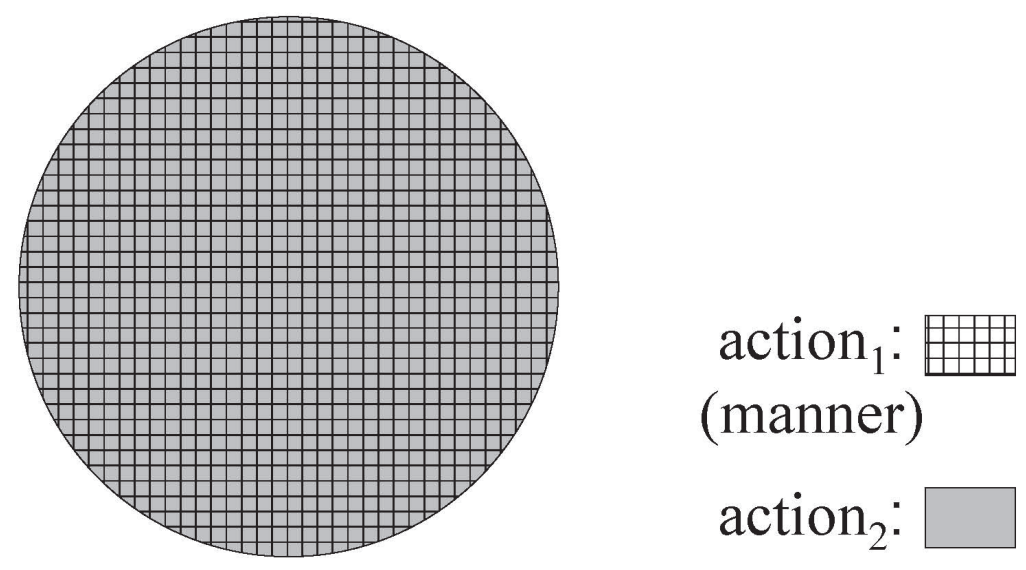

Figure 4: Manner as part of the action 

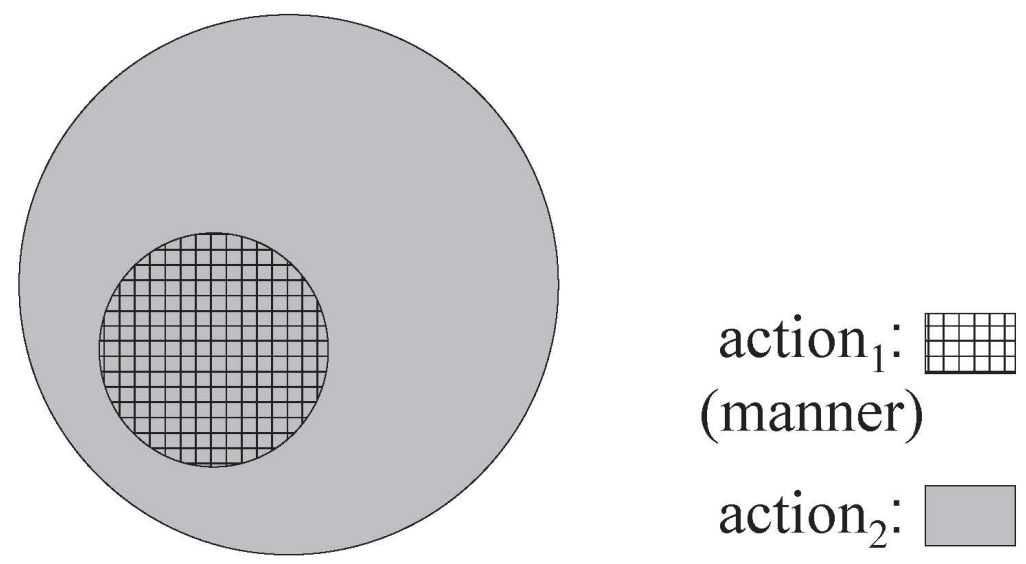

Comparing the two 'form' schemes and the two 'content' schemes, one would immediately notice the similarity between subordination structure and the manner-as-part-of-the-action configuration; in both, the two (main) components are asymmetric and fused. Iconic motivation thus dictates that, other things being equal, subordination structure is more suitable to describe the manner-as-part-ofthe-action situation than coordination structure is. The manner-as-the-wholeaction configuration, on the other hand, resembles subordination structure in that the two components are fused together, but resembles coordination structure in that they are symmetric. This explains why, in contrast to the manner-as-part-ofthe-action configuration, it is compatible either with subordination or coordination structure.

\section{Cross-Linguistic Variation}

Let us now turn to the issue of cross-linguistic variation, illustrated above with examples (2) and (8) repeated below.

(15) a. David pressed the button and opened the door.

b. David poured hot water on the ice and melted it.

(16) a. \#David a appuyé sur le bouton et a ouvert la porte.

b. \#David a versé de l'eau chaude sur la glace et l'a fait fondre.

The contrast between the two pairs of sentences is puzzling, given that they are arguably truth-conditionally synonymous, and also that universality is one of the hallmarks of conversational implicature (e.g., Huang 2007:34-35). ${ }^{7}$

\footnotetext{
${ }^{7}$ To give an example, just as the English sentence 'Some books are interesting' implicates that not all books are interesting, so do its translations in other languages.
} 


\section{The Manner Interpretation of Coordination Structure}

The key to solve this puzzle is the difference in 'niche' between the English and French coordinating constructions. Although the two constructions have analogous structures and share the same literal meaning, they have slightly different niches, or positions in the network of constructions which they are part of. I propose that the manner interpretation of the French coordinating construction is blocked because it has a strong competitor, namely the gérondif construction; that is, upon hearing sentences like (16), the hearer makes the inference: 'If the speaker had meant to convey that the manner relation holds between the two described actions, she would have used the more suitable gérondif,' and concludes that it is not the case that (the speaker believes that) the manner relation holds between the two actions.

Why, then, is the gérondif more suitable than the coordination structure to express the manner interpretation? The reason is three-fold. First, there is iconic motivation. Above I discussed that the manner-as-the-whole-action configuration, where two actions are 'fused' but 'symmetric,' resembles subordination structure to a lesser degree than the manner-as-part-of-the-action configuration does. This 'partial resemblance,' however, still serves as the reason that, other things being equal, subordination structure is at least as suitable as coordination structure to express the manner relation.

Second, the French gérondif is less marked than its counterparts in English. The question at issue can be restated as follows: why is it that in French the speaker has to choose the subordination (gérondif) construction over the coordination construction to describe the manner-as-the-whole-action configuration, while in English the coordination construction too is a viable option in the same situation, as summarized inTable 1 ?

Table 1: Availability of the manner interpretation

\begin{tabular}{|c|c|c|}
\hline & construction type & manner interpretation \\
\hline French & & \\
\hline $\begin{array}{l}\mathrm{VP}_{1} \text { et } \mathrm{VP}_{2} \\
{[\mathrm{VP} \mathrm{V} \ldots[\text { en } \mathrm{V} \text {-ant ...]] }} \\
\text { English }\end{array}$ & $\begin{array}{l}\text { coordination } \\
\text { subordination }\end{array}$ & $\begin{array}{l}\text { unavailable } \\
\text { available }\end{array}$ \\
\hline $\begin{array}{l}\mathrm{VP}_{1} \text { and } \mathrm{VP}_{2} \\
{\left[\begin{array}{l}\mathrm{VP} \\
\mathrm{V}\end{array} \ldots[\mathrm{V} \text {-ing ...]] }\right.} \\
{[\mathrm{VP} \mathrm{V} \ldots[\text {... }[\text { y } \mathrm{V} \text {-ing ...]] }}\end{array}$ & $\begin{array}{l}\text { coordination } \\
\text { subordination } \\
\text { subordination }\end{array}$ & $\begin{array}{l}\text { available } \\
\text { available } \\
\text { available }\end{array}$ \\
\hline
\end{tabular}

Comparing first the English free adjunct and the French gérondif, they differ considerably as to stylistic markedness. Regarding free adjunct (and absolute) constructions, Río-Rey makes the following remark (see also Kortmann 1991):

The received opinion in the literature is that free adjuncts and absolutes are stylistically marked constructions. Thus, both structures are more likely to occur in formal, written, and narrative texts than in informal, oral (or at least speech-based) and non-narrative ones [...] (Río-Rey 2002:313) 


\section{David Y. Oshima}

The gérondif does not share this characteristic.

Comparing next the by $\mathrm{V}$-ing construction and the gérondif, the former can be regarded as formally more marked than the latter. Although both constructions consist of a preposition (by/en) and a present participle potentially followed by complements/modifiers, the role that the preposition plays in each construction is different. In the by $\mathrm{V}$-ing construction, the semantic contribution of by is straightforward; it indicates the relation of means-end. The preposition en (which typically translates as in or to) occurring in the gérondif, on the other hand, does not convey a specific meaning. The gérondif, to some extent analogous to the free adjunct, may indicate a wide range of semantic relations such as 'manner,' 'simultaneity,' 'reason,' and 'condition' (taxonomies vary among scholars), and en does not have a straightforward connection with these interpretations. On this ground, scholars like Halmøy (2003) and Kleiber (2007) maintain that en occurring in the gérondif is not to be considered an independent preposition, but rather is part of a discontinuos expression (en ...-ant). Thus, while the by $\mathrm{V}$-ing construction minimally consists of two units with (relatively) specific meanings (by and a verb in its present participial form, marked by -ing), the gérondif minimally consists of only one (a verb in its 'gérondif form,' marked by [en ...-ant]). It would be fair to say that this makes the former more prolix, and therefore formally more marked, than the latter.

Furthermore, one may argue that the coordinating constructions in English and French are not of equal standing. In the literature, it has been pointed out that languages differ with regard to their preferences as to clause linking patterns. Cosme's (2008) corpus-based contrastive study reveals that, in accordance with previous claims in the contrastive research (e.g., Vinay and Darbelnet 1958), French has a stronger orientation toward hypotaxis (subordination) than English, and conversely, English has a stronger orientation toward parataxis (coordination) than French. Comparing texts with the same contents from the two languages (e.g., a French text and its translation in English), one tends to find cases where an English coordinating construction corresponds to (is translated to or serves as a translation of) a French subordinating construction (such as a gérondif structure or relative clause), whereas the reversed pattern is relatively rare. This implies that the 'standing' of the French coordination construction is somewhat lower than that of the English one.

The aforementioned factors, in conjunction, account for the patterns summarized in Table 1. In French, (i) the relative unmarkedness of the gérondif (in comparison to the corresponding constructions in English), and (ii) general preference for subordination both favor the use of the gérondif in describing two actions standing in the manner relation, leading the hearer to make the inference: 'If the manner relation held between the two actions, the speaker would have used the gérondif.' In English, on the other hand, the markedness of the free adjunct and the by $\mathrm{V}$-ing construction and general preference for coordination provide a reason to choose coordination structure, leading the hearer to infer: 'The speaker 


\section{The Manner Interpretation of Coordination Structure}

may choose coordinating structure even if the manner relation holds between the two actions.'

Finally, the observation made in Section 2 that in French a coordination construction allows the manner interpretation when the result-action is unintentional can be accounted for by Levinson's (2000) M-principle, which, in a simplified form, can be put as: 'What is said in an abnormal way indicates an abnormal situation' or 'Marked messages indicate marked situations.' On the form side, (in French) the coordination structure is not a normal means to indicate, though is not semantically incompatible with, the manner relation. On the content side, a situation where an action typically carried out with intention (e.g., opening a door) is done without intention, as in the case of the curious toddler accidentally opening the door, is marked (not normal). I suggest that the markedness on both sides gives rise to the exceptional manner interpretation of the coordination construction.

\section{Conclusion}

This paper examined conditions under which the VP-coordination structure implicates the manner relation between the two conjuncts. In languages like English, the manner interpretation is available, but due to the effect of iconic motivation, it is restricted to cases where the two described actions have largely overlapping extents (the manner action $\approx$ the modified action). In other languages like French, the VP-coordination construction does not allow the manner interpretation, due to the presence of a construction that is by far more suitable to express the manner relation.

The proposed analysis accounts for the presented facts in English and French, but whether it also applies to a wider range of languages is left open to the future research. It may be of interest, however, to present here some relevant observations on two East Asian languages, Korean and Japanese.

In Korean, a typical way to express the manner relation is the subordinate clause with the polysemous suffix -eselase. The coordination construction with $-k o$, on the other hand, does not easily allow the manner interpretation. ${ }^{8}$ (Speakers' judgments on the interpretation of sentences like (17b) appear to be somewhat unstable.)

a. Pethun-ul nwullese mun-ul yelessta. button-Acc press.ese door-Acc open.Pst.Dcl 'Pressing the button, he opened the door.'

$+>$ Pressing the button is the manner of opening the door.

b. Pethun-ul \{nwulu/nwulless $\}$-ko mun-ul yelessta. button-Acc press/press.Pst-ko door-Acc open.Pst.Dcl

\footnotetext{
${ }^{8}$ A clause with -ese/ase is untensed; a clause with - $k o$ (a non-final conjunct) can optionally be tensed (see, e.g., Lee and Tonhauser 2010).
} 


\title{
David Y. Oshima
}

'He pressed the button and opened the door.'

$+>$ Pressing the button is the manner of opening the door.

\author{
a. Ceskalak-ul sayonghayse pokkumkwukswu-lul mekessta. \\ chopsticks-Acc use.ese fried.noodles-Acc eat.Pst.Dcl \\ 'He ate fried noodles using chopsticks.' \\ $+>$ Using chopsticks is the manner of eating fried noodles. \\ b. Ceskalak-ul \{sayongha/sayonghayss \}-ko pokkumkwukswu-lul \\ chopsticks-Acc use/use.Pst-ko fried.noodles-Acc \\ mekessta. \\ eat.Pst.Dcl \\ 'He used chopsticks and ate fried noodles.' \\ $+>$ Using chopsticks is the manner of eating fried noodles.
}

The situation in Korean is thus reminiscent of the one in French, and this suggests that the statuses (niches) of the $\{e / a\}$ se-construction and the ko-construction are comparable to those of the gérondif and the et-coordination structure, respectively.

A similar pattern is found in Japanese too, where the manner relation can be expressed with semantically underspecified subordination structures where the subordinate clause is headed by a predicate in its infinitive form or gerund form (Oshima 2012), ${ }^{9}$ but cannot be expressed by the coordination structure with the connective -shi.
a. Botan-o \{oshi/oshite $\}$ doa-o aketa. button-Acc press.Inf/press.Ger door-Acc open.Pst 'Pressing the button, he opened the door.' $+>$ Pressing the button is the manner of opening the door.
b. Botan-o oshita-shi doa-o aketa. button-Acc press.Pst-shi door-Acc open.Pst 'He pressed the button and opened the door.' $+>$ Pressing the button is the manner of opening the door.
a. Hashi-o
\{tsukai/tsukatte $\}$ yakisoba-o
tabeta. chopsticks-Acc use.Inf/use.Ger fried.noodles-Acc eat.Pst

${ }^{9}$ An infinitive form is also called ren'yookei, and a gerund form is also called te-form. Complex clauses where the preceding clause is headed by an infinitive or gerund form have sometimes been considered coordination constructions (see Oshima forthcoming, Lee and Tonhauser 2010, and references therein). This view, however, wrongly predicts that a phrase like the following would be unacceptable due to the the Coordinate Structure Constraint.

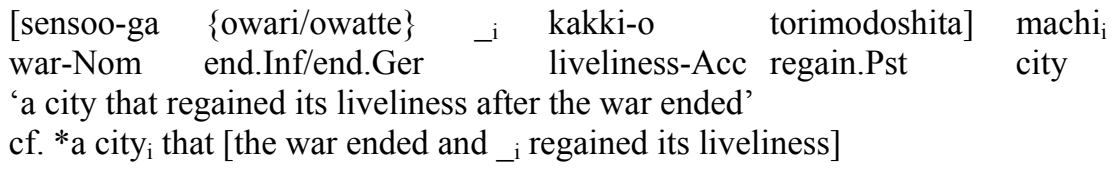


'He ate fried noodles using chopsticks.'

$+>$ Using chopsticks is the manner of eating fried noodles.

b. Hashi-o tsukatta-shi yakisoba-o tabeta.

chopsticks-Acc use.Pst-shi fried.noodles-Acc eat.Pst

'He used chopsticks and ate fried noodles.'

$+>$ Using chopsticks is the manner of eating fried noodles.

It is worth noting that the shi-construction is marked in the sense that its use is relatively infrequent, and tends not to clearly implicate the interclausal relation of 'subsequence', 'causality', etc.

a. Chichi-ga shoku-o \{ushinai/ushinatte\}, haha-ga mata

father-Nom job-Acc lose.Inf/lose.Ger mother-Nom again hataraki-hajimeta.

work-begin.Pst

'My father lost his job and my mother started working again.'

$+>$ The mother started working again because the father lost his job.

b. Chichi-ga shoku-o ushinatta-shi, haha-ga mata

father-Nom job-Acc lose.Pst-shi mother-Nom again

hataraki-hajimeta.

work-begin.Pst

'My father lost his job and my mother started working again.'

$+>$ The mother started working again because the father lost his job.

Korean and Japanese thus conform to the proposed account/generalization. They possess a semantically underspecified and stylistically unmarked subordination structure, and the manner interpretation of coordination structure is blocked.

\section{Acknowledgments}

I would like to thank Junya Watanabe, Fabienne Martin, Nicolas Baumert, France Dhorne, Eve Sweetser, Irene Tamba, Liam Pierce, Yongtaek Kim, Byeong-uk Yi, Ekaterina Tsoy, and the audience of BLS 38 for valuable comments and help. Any remaining errors are my own.

\section{References}

Anscombe, G. E. M. 1976. Intention. Oxford: Basil Blackwell.

Casati, Roberto and Achille Varzi. 2010. Events. In E. N. Zalta, ed., The Stanford Encyclopedia of Philosophy. http://plato.stanford.edu/archives/spr2010/entries/events/.

Cosme, Christelle. 2008. A corpus-based perspective on clause linking patterns in English, French and Dutch. In C. Fabricius-Hansen and W. Ramm, eds., 
David Y. Oshima

'Subordination' versus 'Coordination' in Sentence and Text: A Crosslinguistic Perspective, 89-114. Amsterdam: John Benjamins.

Haiman, John. 1980. The Iconicity of Grammar: Isomorphism and Motivation. Language 56(3):515-540.

Halmøy, Odile. 2007. Le Gérondif en Francais. Gap: Ophrys.

Huang, Yan. 2007. Pragmatics. Oxford: Oxford University Press.

Kleiber, Georges. 2007. En passant par le gérondif avec mes (gros) sabots. Cahier Chronos 19: 93-125.

Kortmann, Bernd. 1991. Free Adjuncts and Absolutes in English: Problems of Control and InterPretation. London: Routledge.

Lee, Jungmee and Judith Tonhauser. 2010. Temporal Interpretation without Tense: Korean and Japanese Coordination Constructions. Journal of Semantics 27(3): 307-341.

Levinson, Stephen C. 2000. Presumptive Meanings: The theory of Generalized Conversational Implicature. Cambridge: MIT Press.

Oshima, David Y. 2012. On the Semantics of the Japanese Infinitive/gerundclause Constructions: Polysemy and Temporal Constraints. Proceedings of the 19th International Conference of HPSG, 292-309. Stanford: CSLI Publications.

Pfeifer, Karl. 1989. Actions and Other Events: The Unifier-Multiplier Controversy. New York: Peter Lang.

Pusch, Luise F. 1980. Kontrastive Untersuchungen zum italienischen "gerundio": Instrumental- und Modalsätze und das Problem der Individuierung von Ereignissen. Tübingen: Max Niemeyer Verlag.

Río-Rey, Carmen. 2002. Subject Control and Coreference in Early Modern English Free Adjuncts and Absolutes. English Language and Linguistics 6(2): 309-323.

Vinay, Jean-Paul and Jean Darbelnet. 1958. Stylistique comparée du français et de l'anglais: Méthode de traduction. Paris: Didier.

Zucchi, Alessandro. 1993. The Language of Propositions and Events. Dordrecht: Kluwer. 
David Y. Oshima

Department of International Communication

Nagoya University

Furo-cho, Chikusa-ku, Nagoya, Japan

oshima@gsid.nagoya-u.ac.jp 